\title{
The effects of high dietary supplements of copper sulphate on pantothenic acid metabolism in the chick
}

\author{
BY EVA A. LATYMER AND MARIE E. COATES \\ National Institute for Research in Dairying, Shinfield, Reading, RG2 $9 A T$
}

(Received 31 March 1980 - Accepted 17 November 1980)

\footnotetext{
1. The effects of incorporation of copper sulphate supplying $250 \mathrm{mg}$ copper/kg semi-purified diet with graded amounts of calcium pantothenate $(\mathrm{CaPa})$ were studied in chicks.

2. When the doses of $\mathrm{CaPa}$ were marginally adequate or less the $\mathrm{Cu}$ supplementation induced severe signs of pantothenic acid $(\mathrm{PaA})$ deficiency.

3. Livers of the $\mathrm{Cu}$-treated birds given low doses of $\mathrm{PaA}$ had lower concentrations of total and bound $\mathrm{PaA}$ than those of the corresponding control birds. The bound:total $\mathrm{PaA}$ value was also reduced.

4. The amount and concentration of coenzyme $A(C o A)$ were significantly less in the livers of $\mathrm{Cu}$-treated chicks. Fatty acid synthetase activity was not reduced.

5. It is suggested that high dietary supplements of $\mathrm{CuSO}_{4}$ induce $\mathrm{PaA}$ deficiency through interference in the biosynthesis of CoA.
}

Although copper sulphate is widely used as a dietary supplement to improve the growth of pigs, its efficiency as a growth-promoter for poultry is doubtful. Whereas some workers have claimed small improvements in chick growth resulting from supplements providing up to $300 \mathrm{mg}$ copper $/ \mathrm{kg}$ diet others have reported no effect or even a growth depression (see review by Smith, 1969). In earlier studies briefly reported by Lloyd et al. (1971) signs of pantothenic acid $(\mathrm{PaA})$ deficiency were observed in chicks given a practical diet supplemented with $250 \mathrm{mg} \mathrm{Cu}$ in the form of $\mathrm{CuSO}_{4} \cdot 5 \mathrm{H}_{2} \mathrm{O}$ and $39 \mathrm{~g}$ maize oil $/ \mathrm{kg}$. When the maize oil was omitted the deleterious effects of the $\mathrm{Cu}$ supplement were much less severe. In chicks given a semi-purified diet containing marginally-sufficient $\mathrm{PaA}$ the $\mathrm{Cu}$ supplement induced severe signs of deficiency of the vitamin and caused a reduction in bound total $\mathrm{PaA}$ in the liver. This suggested possible interference in the metabolic pathways of conversion of $\mathrm{PaA}$ to its biologically-active forms, coenzyme $\mathrm{A}(\mathrm{CoA})$ and the fatty acid synthetase complex (FAS). The experiments reported here were done to investigate some of the metabolic consequences of high dietary $\mathrm{Cu}$ supplementation which might lead to external manifestation of $\mathrm{PaA}$ deficiency in the chick.

\section{EX PERIMENT AL \\ Chicks and diets}

The chicks were the progeny of Rhode Island Red cocks and Light Sussex hens maintained in the Institute's specified pathogen-free breeding unit. They were housed from $1 \mathrm{~d}$ of age in tiered brooders with wire-floored compartments. The initial temperature in the brooding area was $36^{\circ}$ and was gradually reduced to room temperature, approximately $21^{\circ}$, during the following 3 weeks. Food and water were continuously available and artificial light was provided for $14 \mathrm{~h} / \mathrm{d}$.

The semi-purified basal diet had the following composition $(\mathrm{g} / \mathrm{kg})$ : maize starch 602.5 , casein (low vitamin, Calbiochem Ltd, Bishops Stortford) 180.0, gelatin 100.0, L-cystine 3.0, choline chloride 1.5 , myo-inositol 1.0 , maize oil 50.0 , salt mixture 60.0 , vitamin mixture in glucose 2.0. The salt mixture provided ( $/ \mathrm{kg}$ diet) $\mathrm{CaCO}_{3} 17 \cdot 1 \mathrm{~g}, \mathrm{CaHPO}_{4} \cdot 2 \mathrm{H}_{2} \mathrm{O} 17 \cdot 1 \mathrm{~g}$, 
$\mathrm{KH}_{2} \mathrm{PO}_{4} 13.3 \mathrm{~g}, \mathrm{NaCl} 8.67 \mathrm{~g}, \mathrm{MgSO}_{4} \cdot \mathrm{H}_{2} \mathrm{O} 2.67 \mathrm{~g}, \mathrm{FeSO}_{4} .7 \mathrm{H}_{2} \mathrm{O} 670 \mathrm{mg}, \mathrm{MnSO}_{4} .4 \mathrm{H}_{2} \mathrm{O}$ $270 \mathrm{mg}, \mathrm{ZnSO}_{4} .7 \mathrm{H}_{2} \mathrm{O} 130 \mathrm{mg}, \mathrm{KI} 37 \mathrm{mg}, \mathrm{CuSO}_{4} .5 \mathrm{H}_{2} \mathrm{O} 16 \mathrm{mg}$. The vitamin mixture provided (/kg diet) pteroylmonoglutamic acid $1.5 \mathrm{mg}$, thiamin hydrochloride $3.0 \mathrm{mg}$, pyridoxin hydrochloride $4.0 \mathrm{mg}$, riboflavin $6.0 \mathrm{mg}$, nicotinic acid $40.0 \mathrm{mg}$, biotin $200 \mu \mathrm{g}$, cyanocobalmin $20 \mu \mathrm{g}$, Rovimix A-500 (Roche Products, Dunstable, Beds; providing 5.1 $\mathrm{mg}$ retinol) $34 \mathrm{mg}$, menaphthone $5.0 \mathrm{mg}$, DL- $\alpha$-tocopheryl acetate $10.0 \mathrm{mg}$, cholecalciferol $40 \mu \mathrm{g}$, all dissolved in the maize oil. Where appropriate calcium pantothenate $(\mathrm{CaPa})$ was included at doses between 0 and $20.25 \mathrm{mg} / \mathrm{kg}$ diet and in $\mathrm{Cu}$-supplemented diets finely powdered $\mathrm{CuSO}_{4} .5 \mathrm{H}_{2} \mathrm{O}$ was incorporated at the rate of $1 \mathrm{~g} / \mathrm{kg}$, equivalent to $250 \mathrm{mg} \mathrm{Cu} / \mathrm{kg}$. After mixing, the diets were moistened with water, granulated by passing through a sieve of $5 \mathrm{~mm}$ mesh, then dried on stainless steel trays in a current of air at $\mathbf{4 2}^{\circ}$.

\section{Analytical procedures}

Preparation and storage of liver samples. Chicks were killed by cervical dislocation and the livers were immediately removed and plunged into liquid nitrogen, then homogenized on ice for $3 \mathrm{~min}$. The homogenized samples were divided among several vials, frozen and kept at $-20^{\circ}$ until taken for analysis.

Microbiological assays. $\mathrm{PaA}$ activity was measured microbiologically using Lactobacillus plantarum strain NCDO 82, ATAA 8014 by an assay procedure similar to that described by Bird (1963). Free PaA was determined in extracts of liver prepared by heating homogenized samples with $0.14 \mathrm{M}$-sodium phosphate buffer at $\mathrm{pH} 6.6$ for $10 \mathrm{~min}$ at $115^{\circ}$, cooling and adjusting to $\mathrm{pH} 4 \cdot 6$, filtering and adjusting to $\mathrm{pH} 6 \cdot 8$. Total (free plus bound) $\mathrm{PaA}$ was determined after treatment of the liver homogenate with alkaline phosphatase and chick liver enzyme (Barton Wright, 1963).

Determination of COA. Total CoA was measured by a kinetic enzymic assay based on that described by Allred \& Guy (1969). It makes use of the fact that, when all other components of the reaction mixture are in excess, $\mathrm{CoA}$ is the rate-limiting substance in the following coupled enzyme system:

$$
\begin{array}{ll}
\text { acetyl phosphate }+\mathrm{CoASH} & \rightarrow \text { acetyl CoA }+ \text { phosphate } \\
\text { acetyl CoA + oxalacetate } & \rightarrow \text { citrate + CoASH } \\
\text { malate+NAD } & \rightarrow \text { oxalacetate + NADH. }
\end{array}
$$

Measurements were made on deproteinized liver samples prepared by homogenizing in perchloric acid, centrifuging at $4^{\circ}$ for $5 \mathrm{~min}$ at $1500 \mathrm{~g}$, decanting the supernatant fraction and adjusting to $\mathrm{pH} 3 \cdot 5$. After standing on ice for $1 \mathrm{~h}$ the samples were again centrifuged as described previously and the supernatant fraction collected. Before assay the deproteinized extracts and the standard CoA preparation were treated with dithiothreitol to ensure that the CoA was in the reduced form. The rate of formation of NADH was measured spectrophotometrically as an increase of absorbance at $340 \mathrm{~nm}$. Test samples were compared with a standard preparation of CoASH (ChromatoPure, free acid, International Enzymes Ltd, Windsor, Berks).

Measurement of FAS complex activity. The assays were done on freshly-prepared supernatant fractions obtained by centrifuging the liver homogenates at $200000 \mathrm{~g}$ for 30 min at $4^{\circ}$. The method was based on that of Martin et al. (1961), in which the FAS in the test solution catalyses the incorporation of acetyl CoA into fatty acids, resulting in a decrease in absorbance. Since no standard sample of FAS complex was available the results were expressed in units suggested by Martin et al. (1961), i.e. the amount of enzyme required to give a decrease in absorbance of 0.100 optical density at $340 \mathrm{~nm}$ in 3 min was defined as 1 unit of activity.

Experimental design. Four experiments were done with chicks given graded amounts of 
$\mathrm{CaPa}$ at and below the estimated dietary requirement, with or without a supplement of $\mathrm{CuSO}_{4} .5 \mathrm{H}_{2} \mathrm{O}$ providing $250 \mathrm{mg} \mathrm{Cu} / \mathrm{kg}$ diet. The doses of $\mathrm{CaPa}$ were chosen in geometric progression in the proportion 3:2. In Expt 1 the doses were $6.0,13.5$ and $20.25 \mathrm{mg} / \mathrm{kg}$ diet, but as all three appeared to satisfy the chick's requirement for the vitamin the doses were reduced in the other three experiments to $2.67,4.0$ and $6.0 \mathrm{mg} / \mathrm{kg}$ diet. Microbiological assays made on several of the diets showed that there was no loss of PaA during the course of an experiment. Duplicate groups of ten birds were allotted to each treatment, usually five males and five females, at $1 \mathrm{~d}$ of age. They were weighed at weekly intervals and examined daily for signs of $\mathrm{PaA}$ deficiency, namely, lesions at the corners of the mouth, encrusted eyelids, sores on the upper surface of the feet and neurological disorders manifested by a staggering gait. Experiments were terminated during the fourth week, before the effects of the deficiency were so severe as to cause many deaths among birds on the lowest levels of $\mathrm{PaA}$ supplementation, and the livers were analysed for $\mathrm{PaA}$ or its derivatives.

The dietary supplements of $\mathrm{CaPa}$, the analyses performed on the livers and the duration of the experiments were as follows:

Expt 1 6.0, 13.5 and $20.25 \mathrm{mg} / \mathrm{kg}$; free and total $\mathrm{PaA}$ at $24 \mathrm{~d}$.

Expt $22 \cdot 67,4 \cdot 0$ and $6.0 \mathrm{mg} / \mathrm{kg}$; free and total $\mathrm{PaA}$ and $\mathrm{CoA}$ at $25 \mathrm{~d}$.

Expt $32.67,4 \cdot 0$ and $6.0 \mathrm{mg} / \mathrm{kg}$; CoA at $21 \mathrm{~d}$.

Expt $42.67,4.0$ and $6.0 \mathrm{mg} / \mathrm{kg}$; FAS complex at $21 \mathrm{~d}$.

Statistical treatment of results. In Expts 1, 3 and 4 the livers from all birds of the same sex within a cage were combined before analysis. In Expt 2 individual livers were analysed and the results averaged to give two values for each cage, one for each sex. Body-weights were similarly averaged to give two values for each cage. The values were subjected to analysis of variance, the variation being divided into between-cage and within-cage variation. The between-cage value was further subdivided into variation between dietary treatments and the pooled residual variation between cages, which was used to test the significance of the diet effects. The same residual value was used to calculate the standard errors of differences between diet means. The variation within cages was divided between sex, sex $\times$ dietary treatment interaction and the pooled residual variation within cages. This last value was used to test the significance of sex and sex $x$ diet effect.

\section{RESULTS}

\section{Growth rates and signs of deficiency}

The effects of the different treatments on body-weights, incidence of signs of deficiency of $\mathrm{PaA}$ and mortality are summarized in Table 1 . In all experiments at all levels of $\mathrm{CaPa} \mathrm{Cu}$ supplementation resulted in lower body-weights than those of the unsupplemented chicks. At the higher doses of the vitamin chosen in Expt 1 the depression of growth was small, but in the other three experiments when the dietary supply of CaPa was near to or below the marginal requirement the reduction in growth of the Cu-fed chicks was highly significant $(P<0.001)$. In all experiments the clinical signs of deficiency appeared earlier and affected a larger number of chicks in the $\mathrm{Cu}$-supplemented groups when the diet contained $6 \mathrm{mg}$ $\mathrm{CaPa}$ or less $/ \mathrm{kg}$. Mortality was also higher in chicks given submarginal amounts of the vitamin, and the deaths occurred at an earlier age.

\section{Concentration of free and bound $\mathrm{PaA}$ in the livers}

As a consequence of the lower body-weight the livers of $\mathrm{Cu}$-treated birds were smaller than those of the corresponding controls, the effect being more apparent at the lower doses of $\mathrm{CaPa}$ (Table 2). In Expt 1, in which high doses of the vitamin were used, whether $\mathrm{Cu}$ was supplemented or not, there was little difference in the concentration of total or bound 
Table 1. Mean body-weights ( $\mathrm{g}$ ), number of birds with signs of pantothenic acid deficiency and mortality in groups of chicks reared on different doses of dietary calcium pantothenate $(\mathrm{CaPa})$ with or without a supplement of $250 \mathrm{mg}$ copper as $\mathrm{CuSO}_{4} .5 \mathrm{H}_{2} \mathrm{O} / \mathrm{kg}$ diet

(Means of two $\times$ ten chicks)

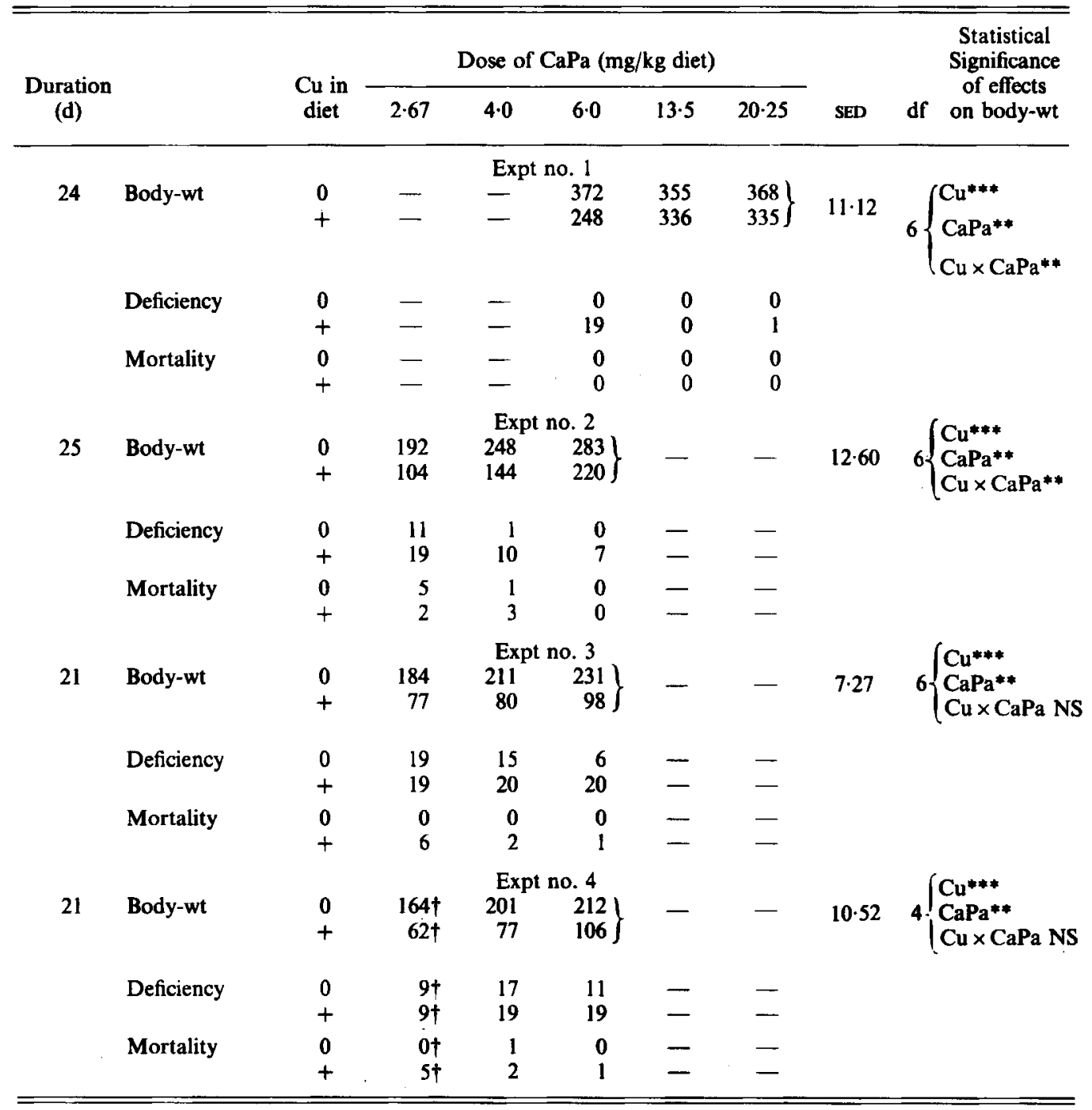

NS, not significant.

SED, standard error of differences of means.

$\mathrm{CaPa}$, calcium pantothenate.

** $P<0.01, * * * P<0.001$.

$\dagger$ Group of ten chicks discarded due to an accidental break in the water supply. 
Table 2. Concentration $(\mathrm{nm} / \mathrm{g})$ of total, bound and bound: total pantothenic acid $(\mathrm{PaA})$ in livers of chicks reared on different doses of dietary calcium pantothenate $(\mathrm{CaPa})$ with or without a supplement of $250 \mathrm{mg}$ copper as $\mathrm{CuSO}_{4} .5 \mathrm{H}_{2} \mathrm{O} / \mathrm{kg}$ diet

(Means of two $\times$ ten chicks)

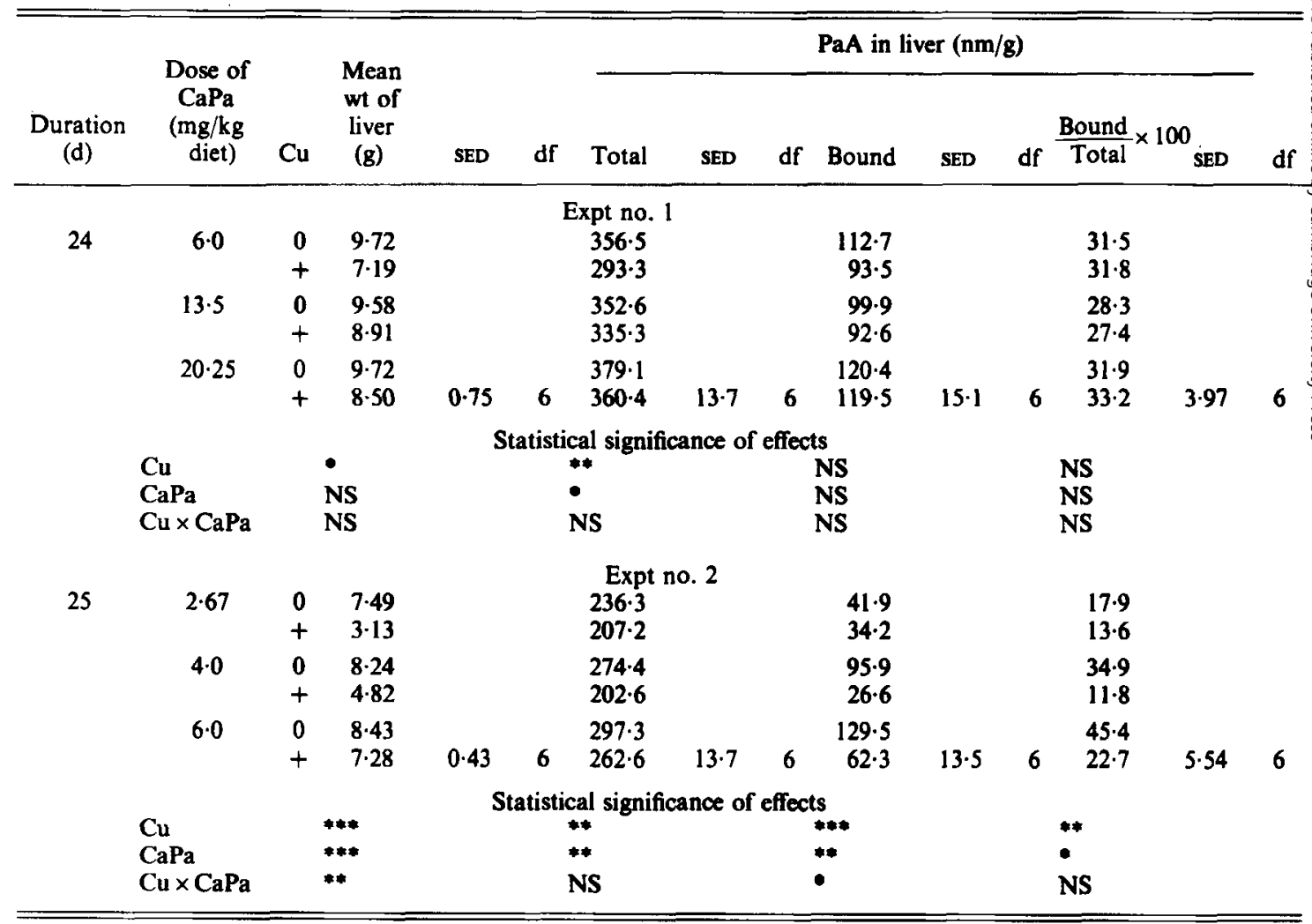

NS, not significant.

$\mathrm{CaPa}$, calcium pantothenate.

$\mathrm{PaA}$, pantothenic acid.

SED, standard error of differences of means.

$* P<0.05, * * P<0.01, * * * P<0.001$.

$\mathrm{PaA}$ in the livers, except at the lowest supplement $(6.0 \mathrm{mg} / \mathrm{kg} \mathrm{diet})$ of $\mathrm{CaPa}$, when the concentration of both forms of the vitamin was somewhat reduced. In Expt 2, in which the supplements of $\mathrm{CaPa}$ were lower, total and bound $\mathrm{PaA}$ were reduced by the $\mathrm{Cu}$ treatment at all levels of the vitamin supplementation and bound: total $\mathrm{PaA}$ was significantly $(P<0.01)$ less in the Cu-treated groups. On this occasion the diet with $6.0 \mathrm{mg} \mathrm{CaPa} / \mathrm{kg}$ supported poorer growth and the effect of $\mathrm{Cu}$ supplement on the concentration of bound $\mathrm{PaA}$ was more severe than had been observed in Expt 1.

Effect of $\mathrm{Cu}$ supplement on CoA concentration in the livers

The concentrations of $\mathrm{CoA}$ in the livers of chicks with and without the supplement of $\mathrm{CuSO}_{4} \cdot 5 \mathrm{H}_{2} \mathrm{O}$ are shown in Table 3 . The concentration was not increased with increasing doses of dietary $\mathrm{CaPa}$ but was significantly reduced in both experiments by the supplement of $\mathrm{CuSO}_{4} \cdot \mathrm{SH}_{2} \mathrm{O}$. 
Table 3. Concentration of coenzyme $A(C o A)$ in the livers of chicks reared on different doses of dietary calcium pantothenate $(\mathrm{CaPa})$ with and without a supplement of $250 \mathrm{mg}$ copper as $\mathrm{CuSO} \mathrm{O}_{4} \cdot 5 \mathrm{H}_{2} \mathrm{O} / \mathrm{kg}$ diet

(Means of two $\times$ ten chicks)

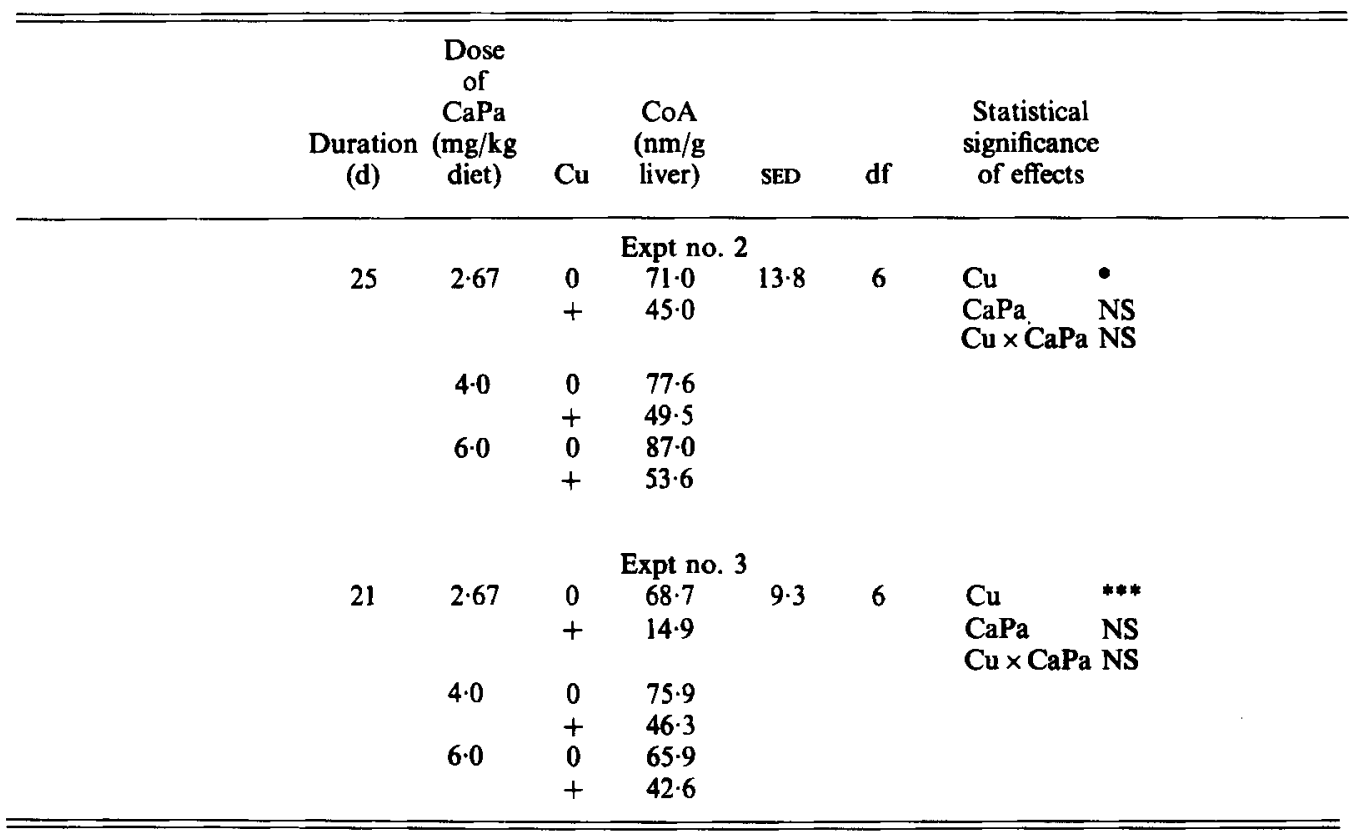

NS, not significant.

SED, standard error of differences of means.

$\mathrm{CaPa}$, calcium pantothenate.

CoA, coenzyme A

${ }^{*} P<0.05,{ }^{* * *} P<0.001$.

\section{Effect of $\mathrm{Cu}$ supplement on FAS activity}

The FAS activity (Table 4) was not affected by the Cu treatment except at the lowest dose of dietary $\mathrm{PaA}(2.67 \mathrm{mg} / \mathrm{kg})$ where there was a small significant increase $(P<0.05)$. No significant effect of increasing the dietary supplement of $\mathrm{CaPa}$ was observed.

\section{DISCUSSION}

There was considerable variation between experiments in the growth of chicks given similar supplements of $\mathrm{CaPa}$. In particular, body-weights of chicks given $6.0 \mathrm{mg} \mathrm{CaPa} / \mathrm{kg}$ diet were much greater in Expt 1 than in the later experiments. This presumably reflects differences in age and state of lay of the parent flock, which would be expected to influence the performance of the chicks and possibly the reserves of $\mathrm{PaA}$ carried over in their eggs. However, in none of the experiments was increased growth observed in any of the groups given the $\mathrm{Cu}$ supplement. On the contrary, on almost every occasion the body-weights achieved by the supplemented birds were significantly less than those of their controls, except 
Table 4. Fatty-acid synthetase activity (/g liver) of chicks reared to $21 \mathrm{~d}$ on different doses of dietary calcium pantothenate $(\mathrm{CaPa})$ with or without a supplement of $250 \mathrm{mg}$ copper as $\mathrm{CuSO}_{4} \cdot 5 \mathrm{H}_{2} \mathrm{O} / \mathrm{kg}$ diet

(Means from pooled samples of livers)

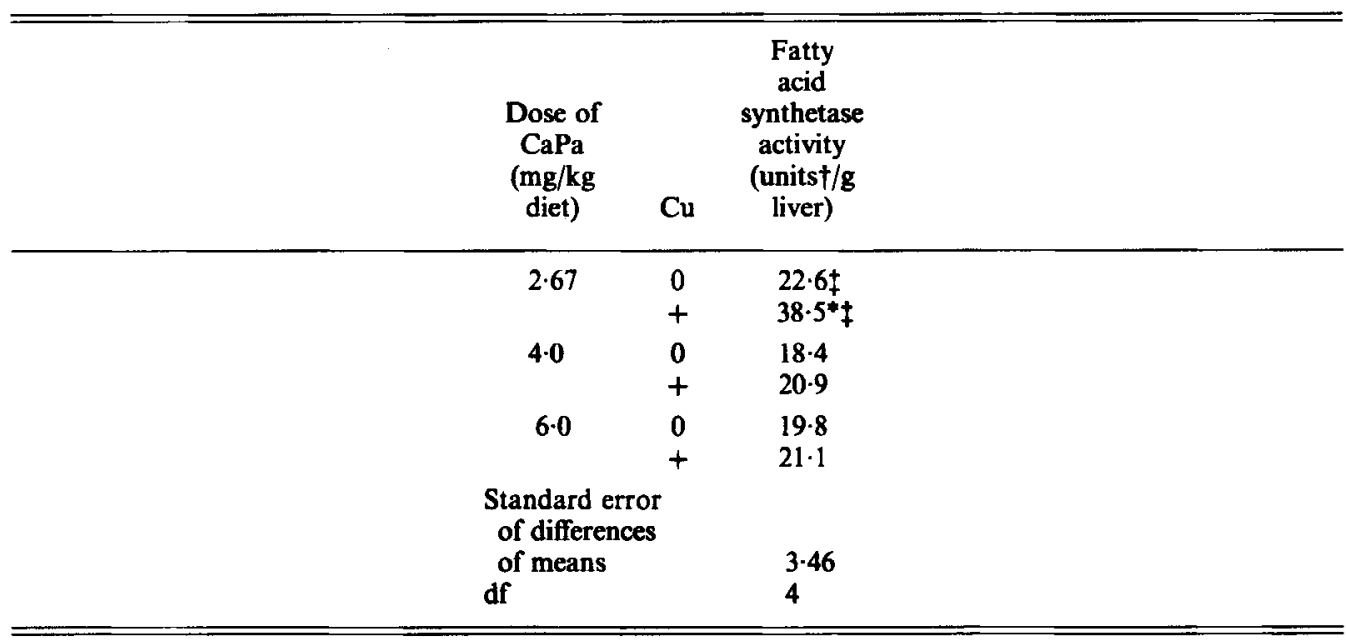

- Significantly different from value for unsupplemented diet $(P<0.05)$.

$\dagger$ One unit of activity is the amount of enzyme required to give a decrease in absorbance at $340 \mathrm{~nm}$ of 0.100 in $3 \mathrm{~min}$.

\$ Two missing values.

at the highest dose of dietary $\mathrm{CaPa}(20.25 \mathrm{mg} / \mathrm{kg})$, when growth was approximately the same on the supplemented and unsupplemented diets.

The results of all four experiments confirmed the earlier findings of Lloyd et al. (1971) that a dietary supplement of $250 \mathrm{mg} \mathrm{Cu}$ as $\mathrm{CuSO}_{4} \cdot 5 \mathrm{H}_{2} \mathrm{O}$ consistently evoked signs of $\mathrm{PaA}$ deficiency in chicks. On diets containing marginally adequate amounts or less of $\mathrm{CaPa}$, inclusion of the $\mathrm{Cu}$ salt induced a higher mortality and increased occurrence of clinical signs of deficiency, but the detrimental effects were not pronounced on diets containing $13.5 \mathrm{mg}$ or more of $\mathrm{CaPa} / \mathrm{kg}$.

In the livers of the $\mathrm{Cu}$ treated birds the contents of total $\mathrm{PaA}$ (free plus bound) were less than in those of the corresponding control birds. This was partly due to the smaller size of the livers, but there was also a reduced concentration of $\mathrm{PaA}$, particularly in Expt 2 on diets containing the $\mathrm{Cu}$ supplement and the lower doses of $\mathrm{CaPa}$. The content of bound $\mathrm{PaA}$ was reduced even more than that of the total $\mathrm{PaA}$, so that bound: total $\mathrm{PaA}$ value was significantly decreased. This effect was not apparent in Expt 1, in which higher dietary amounts of $\mathrm{CaPa}$ were used.

Although the signs of deficiency increased with decreasing amounts of dietary $\mathrm{CaPa}$, and were more severe in the $\mathrm{Cu}$-treated chicks, the pattern of clinical deficiency was not closely correlated with the concentrations of $\mathrm{CoA}$ or of $\mathrm{PaA}$ in the livers. This is not surprising since it is questionable whether liver content is a good indicator of vitamin status. It was observed in earlier work (Coates et al. 1968) that birds showing acute signs of deficiency of vitamins of the $\mathrm{B}$ complex, including $\mathrm{PaA}$, nevertheless had appreciable liver reserves of the deficient vitamin. In rats $\mathrm{CoA}$ concentration in the liver was not significantly influenced by increasing dietary amounts of $\mathrm{CaPa}$, nor was bound $\mathrm{PaA}$ concentration increased by supplements of $\mathrm{PaA}$ well above the dietary requirement (Nakamura, 1969; Nakamura et al. 1969). The bound forms of $\mathrm{PaA}$ that may occur in liver include $\mathrm{CoA}$, the 
FAS complex and intermediates in their biosynthesis. In the two experiments in which CoA was measured, a considerable reduction both in total amount and in concentration was observed in the livers of $\mathrm{Cu}$-treated chicks. On some occasions concentration of bound $\mathrm{PaA}$ was apparently less than that of $\mathrm{CoA}$ measured on the same samples (Expt 2). These discrepancies could have been due to imprecision of measurement, since the methods of assay for both substances are subject to large errors and only small amounts of sample were available. FAS was not reduced, and even showed a small significant increase in the group receiving the lowest dose of dietary $\mathrm{CaPa}$, which cannot be readily explained. Since several birds in this group had already died from deficiency exacerbated by the $\mathrm{Cu}$-treatment the result was obtained on only a few survivors and may thus have been spuriously high.

In micro-organisms the biosynthesis of $\mathrm{COA}$ and the acyl carrier protein (ACP), an essential component of the FAS complex, follows a common pathway from $\mathrm{PaA}$ via $4^{\prime}$-phosphopantothenyl cysteine to $4^{\prime}$-phosphopantetheine. The subsequent formation of dephospho-CoA and its phosphorylation to CoA have been reasonably well established but the metabolic sequence from 4'-phosphopantetheine to ACP and FAS has not yet been elucidated. In animal tissues the biosynthesis of CoA follows a similar pathway and it is known that 4'-phosphopantetheine is an essential component of FAS. From the greatly reduced concentration of $\operatorname{CoA}$, and the lack of inhibition of FAS activity, it might be inferred that $\mathrm{Cu}$ supplementation interferes on the metabolic pathway between $4^{\prime}$ phosphopantetheine and CoA. However, in the light of findings with micro-organisms and in rats the inference is open to question. For example, Das \& Toennies (1969) showed that Streptococcus faecalis produced both $\mathrm{CoA}$ and $\mathrm{ACP}$ when grown with adequate $\mathrm{PaA}$, but when the $\mathrm{PaA}$ content of the medium was restrictive the CoA disappeared. Other workers observed that rats on the verge of death from $\mathrm{PaA}$ deficiency nevertheless had normal liver levels of FAS activity (Larrabee et al. 1965). In both these systems it appears that FAS activity was maintained at the expense of other $\mathrm{PaA}$-containing compounds. If the same is true for the chick, limitation in supply of any of the intermediates on the common pathway could explain the observed results. One possible effect of the $\mathrm{Cu}$ treatment might be interference in the formation of $4^{\prime}$-phosphopantothenyl cysteine. Studies in vitro by Hanaki \& Kamide (1975) showed that autoxidation of cysteine was catalysed by cupric ions under aerobic and anaerobic conditions. Robbins \& Baker (1980) suggested that although cystine is completely utilized by the normal bird, in the $\mathrm{Cu}$-supplemented chick formation of cysteine-copper or glutathione-copper complexes or both would necessarily limit available cysteine. If the processes suggested by these authors are proved to be correct, the reaction of cysteine with phosphopantothenic acid, during CoA formation, could be adversely affected through the limited availability of cysteine. The findings of Nakamura et al. (1967) that hepatic CoA was greatly reduced in methionine deficiency in the rat and of Verma \& Motzok (1979) who reported enhanced CoA synthesis in chicks by increasing DL-methionine or $\mathrm{SO}_{4}$ as $\mathrm{CaSO}_{4} .2 \mathrm{H}_{2} \mathrm{O}$ in the diet lend further support to the suggested possibility of interference of $\mathrm{Cu}$ in the formation of $\mathrm{CoA}$.

The poorer growth of the $\mathrm{Cu}$-supplemented chicks was inevitably accompanied by a reduced intake of food and thus of $\mathrm{CaPa}$. This is unlikely to have been the cause of the increased incidence of deficiency as the requirement for vitamins is generally considered to be related to the amount of food eaten (Agricultural Research Council, 1975). No significant loss of $\mathrm{CaPa}$ from the diet occurred during the course of the experiment, but the possibility remains that the presence of $\mathrm{Cu}$ caused some destruction of $\mathrm{PaA}$ in the gut.

From earlier reports it appears that the deleterious effects of high dietary supplements of $\mathrm{CuSO}_{4}$ are influenced by other components of the diet. Coates \& Harrison (1959) observed little or no growth depression when a diet low in animal protein was supplemented with $1 \mathrm{~g} \mathrm{CuSO}_{4} \cdot 5 \mathrm{H}_{2} \mathrm{O} / \mathrm{kg}$ but significantly poorer growth with the same supplement in a diet 
of normal animal protein content. Lloyd et al. (1971) reported that the presence of maize oil in the diet considerably exacerbated the harmful effects of $\mathrm{CuSO}_{4}$ and, more recently, Jensen \& Maurice (1979) demonstrated the protective effect of sulphur amino acids against $\mathrm{Cu}$ toxicity in chicks. These possible influences are being separately investigated. None of them could be examined in the experiments now reported since the diet contained ample casein and cystine, with maize oil as the source of fat. In these circumstances it is clear that the harmful effects of including high levels of $\mathrm{CuSO}_{4}$ in a chick diet are due to induction of a deficiency of PaA, probably because the synthesis of CoA from PaA is inhibited.

The authors are grateful to Dr D. Hewitt for advice and assistance with the statistical treatment of the results and to Dr J. E. Ford and his colleagues for the use of their facilities for the microbiological assays.

\section{REFERENCES}

Agricultural Research Council (1975). The Nutrient Requirements of Farm Livestock. No. 1. Poultry, 2nd ed., p. 93. London: Agricultural Research Council.

Allred, J. B. \& Guy, D. G. (1969). Analyt. Biochem. 29, 293.

Barton Wright, E. C. (1963). Reprinted from Laboratory Practice. London: United Trade Press.

Bird. O. D. (1963). In Analytical Microbiology, p. 497 [F. Kavanagh, editor]. New York and London: Academic Press.

Coates, M. E., Ford, J. E. \& Harrison, G. F. (1968). Br. J. Nutr. 22, 493.

Coates, M. E. \& Harrison, G. F. (1959). Br. J. Nutr. 13, 345.

Das, D. N. \& Toennies, G. (1969). J. Bact. $98,898$.

Hanaki, A. \& Kamide, H. (1975). Chem. Pharmac. Bull. 23, 1671.

Jensen, J. S. \& Maurice, D. V. (1979). J. Nutr. 109, 91.

Larrabee, A. R., McDaniel, E. G., Bakerman, H. \& Vagelos, P. R. (1965). Proc. natn. Acad. Sci. USA 54, 267.

Lloyd, D. R., Jenkins, N. K., Coates, M. E., Harrison, G. F. \& Morris, T. R. (1971). Proc. Nutr. Soc. 31, 34A.

Martin, D. B., Horning, M. G. \& Vagelos, P. R. (1961). J. biol. Chem. 236, 663.

Nakamura, T. (1969). Vitamins, Kyoto, 40, 1.

Nakamura, T., Kusunoki, T. \& Kataoka, S. (1967). J. Vit. 13, 283.

Nakamura, T., Kusunoki, T., Soyama, K., Tsujita, K. \& Tanaka, K. (1969). Vitamins, Kyoto, $40,354$.

Robbins, K. R. \& Baker, D. H. (1980). Poult. Sci. 29, 1246.

Smith, M. S. (1969). Br. Poult. Sci., 10, 97.

Verma, R. S. \& Motzok, I. (1979). Nutr. Rep. Int. $20,735$. 